\title{
Cytotoxic activity of 2-Fluoro-ara-AMP and 2-Fluoro-ara-AMP- loaded erythrocytes against human breast carcinoma cell lines
}

\author{
FRANCESCA PIERIGÈ $^{1}$, CINZIA DE MARCO ${ }^{2}$, NICOLA ORLOTTI ${ }^{2}$, SABRINA DOMINICI $^{1}$, SARA BIAGIOTTI $^{1}$, \\ SONJA SERAFINI ${ }^{1}$, NADIA ZAFFARONI ${ }^{2}$, MAURO MAGNANI $^{1}$ and LUIGIA ROSSI ${ }^{1}$ \\ ${ }^{1}$ Department of Biomolecular Sciences, University of Urbino, 61029 Urbino (PU); ${ }^{2}$ Department \\ of Experimental Oncology and Molecular Medicine, Fondazione Istituto Di Ricovero \\ e Cura a Carattere Scientifico Istituto Nazionale dei Tumori, Milan, Italy
}

Received January 22, 2010; Accepted March 19, 2010

DOI: 10.3892/ijo_00000661

\begin{abstract}
Fludarabine phosphate (2-Fluoro-ara-AMP) is a purine analogue approved for the clinical treatment of haematological malignancies. This antimetabolite has also shown 'in vitro' antiproliferative activity against experimental models of solid mammary tumor. In this perspective, we have determined the cytotoxic effects of 2-Fluoro-ara-AMP against two human breast cancer cell lines (the ER-positive MCF-7 and the ER-negative MDA-MB-435), by adding the drug both in its free form and encapsulated into erythrocytes, as a strategy to modify the pharmacokinetic profile of the compound in order to increase its efficacy and decrease its toxicity. Similar antiproliferative activity of 2-Fluoro-araAMP in the two cell lines was obtained, reaching an almost complete abrogation of growth already after just $24 \mathrm{~h}$ of free drug exposure at all the tested doses. Meanwhile, encapsulated 2-Fluoro-ara-AMP was successfully released from erythrocytes into the culture media in a time-dependent manner with an efficacy comparable to that of the free drug treatment. This result suggests the possibility of administering 2-Fluoro-araAMP in patients with breast cancer using autologous erythrocytes as a system to slowly and constantly deliver 2-Fluoroara-A into circulation. In addition, possible mechanisms involved in the antiproliferative activity of 2-Fluoro-araAMP, such as the effects on cell cycle progression, p53 expression and STAT1 pathway activation in $\mathrm{ER}^{+}$and ER cancer cell lines, are proposed.
\end{abstract}

\section{Introduction}

Fludarabine phosphate (9-b-D-arabinofuranosyl- 2-fluoroadenine 5'-monophosphate, 2-Fluoro-ara-AMP), known as

Correspondence to: Professor Luigia Rossi, Dipartimento di Scienze Biomolecolari, Università degli Studi di Urbino 'Carlo Bo', Via Saffi, 2-61029 Urbino, Italy

E-mail: luigia.rossi@uniurb.it

Key words: solid mammary tumor, fludarabine phosphate, drug delivery, loaded erythrocytes, p53 expression, STAT1 pathway activation
Fludara, is a fluorinate purine analogue showing antineoplastic activity. It first entered into clinical trials in 1982 for treatment of lymphocytic haematological malignancies and, successively, was approved for use in the management of patients with chronic lymphocytic leukaemia (1-7).

Unlike adenine arabinoside (ara-A), the clinical formulation of 2-Fluoro-ara-AMP is water soluble and resistant to deamination by adenosine deaminase (8-10). It functions as a prodrug that is instantaneously and quantitatively dephosphorylated to the parent nucleoside 2-Fluoro-ara-A upon intravenous infusion, probably by the 5'-nucleotidase activity in plasma, and then transported into the cell by facilitated transport $(11,12)$. Inside the cells, rephosphorylation occurs which, in the end, leads to fluoroadenine arabinoside triphosphate (2-Fluoro-ara-ATP), the principal cytotoxic metabolite of 2-Fluoro-ara-AMP. This metabolite acts on several key processes necessary for DNA replication and repair which finally results in the complete inactivation of DNA synthesis followed by cellular apoptosis. The complete mechanism by which 2-Fluoro-ara-AMP induces apoptosis in cancer cells is not yet fully understood (13).

Even if until now 2-Fluoro-ara-AMP has been used clinically mostly in haematological diseases, its significant antitumor activity has prompted us to investigate the possibility of using it against experimental models of breast cancer, a tumor that represents the most common type of cancer in women. In fact, notwithstanding the advancement in treatment for this disease, a considerable number of patients are intrinsically resistant to conventional chemotherapy or develop resistance after treatment. In this context, the identification of new treatment strategies for this malignancy would be of great benefit. In order to work with experimental models that are representative of the clinical situation, two established cell lines having a different profile of estrogen receptor (ER) expression, MCF-7 (ER-positive) and MDAMB-435 (ER-negative), were used to evaluate and characterize the antiproliferative activity of 2-Fluoro-ara-AMP. It is known that triphosphate analogues inhibit various processes involved in DNA and RNA synthesis (14-16), however, their effects may involve modulation of apoptotic pathways, cell cycle control, or signal transduction pathways (17). Since 2Fluoro-ara-AMP is a potent activator of both p53, a transcription factor able to block the cell cycle (18), and of STAT1, 
a transcription factor playing an important role in growth arrest of cancer cell lines (19-21), a possible mechanism to explain the effect of 2-Fluoro-ara-AMP on $\mathrm{ER}^{+}$and ER breast tumor cell lines involving p53 expression and STAT1 activation, was investigated.

Moreover, considering the drug dose limiting toxicity $(22,23)$, it would be necessary to investigate the possibility of slowly releasing the active drug 2-Fluoro-ara-A through a delivery system able to modify the drug pharmacokinetic profile. It is known that erythrocytes constitute potential biocompatible carriers for different bioactive substances, as well as conventional therapeutics, being able to affect drug pharmacokinetic, drug bioavailability and sometime safety and efficacy (24). Besides, it is interesting to note that red blood cells are 'active' carrier systems, endowed with a number of enzymatic activities that can be conveniently explored to convert an inactive pro-drug into an active drug. It is suitable for 2-Fluoro-ara-AMP that can be encapsulated into human erythrocytes since it is synthesized with charged group on the sugar moiety making it non-diffusible and, when the chemical group has been hydrolyzed by resident red cell enzymes, the pro-drug can be converted into its diffusible form crossing the red cell membrane and thus slowly released in circulation (25). For this reasons, the antitumor activity of 2-Fluoro-araAMP-loaded erythrocytes on MCF-7 and MDA-MB-435 cell lines was evaluated.

\section{Materials and methods}

Materials. 2-Fluoro-ara-AMP (Fludara) was obtained from Shering S.p.A. (Segrate, Milan, Italy). Human erythrocytes and human plasma were from freshly drawn human blood from healthy donors collected in heparinized tubes.

\section{Methods}

Pharmacokinetics of 2-Fluoro-ara-AMP in culture media. To be taken up by breast cells, 2-Fluoro-ara-AMP added to culture media first has to be converted to its dephosphorylated form 2-Fluoro-ara-A. To this end, $0.3 \mathrm{mM}$ 2-Fluoro-ara-AMP was added to culture media at $37^{\circ} \mathrm{C}$ for $72 \mathrm{~h}$. At different time intervals $(0,1,3,5,8,24,32,48$ and $72 \mathrm{~h})$ 2-Fluoro-ara-AMP and the corresponding dephosphorylated derivative were determined by high-performance liquid chromatography (HPLC) of perchloric acid extracts. These were prepared following the method reported by Beutler, slightly modified. Briefly, $50 \mu \mathrm{l}$ of $10 \%(\mathrm{v} / \mathrm{v}) \mathrm{HClO}_{4}$ was added to $0.1 \mathrm{ml}$ of medium aliquots; after centrifugation at $1,800 \mathrm{x} \mathrm{g}$ for $10 \mathrm{~min}$, the supernatant was separated and neutralized with $\mathrm{K}_{2} \mathrm{CO}_{3}$. The solution was again centrifuged at $1800 \mathrm{x}$ g for $10 \mathrm{~min}$ and the supernatant was removed and brought to a final volume of $200 \mu \mathrm{l}$. Preliminary experiments have demonstrated that this drug and its metabolites are stable under these extraction conditions (not shown). Samples were then filtered and $50 \mu 1$ aliquots were used for HPLC analysis as described below.

Metabolism of 2-Fluoro-ara-AMP in MCF-7 and MDA-MB435 cell lines. MCF-7 and MDA-MB-435 cells were incubated at $37^{\circ} \mathrm{C}$ in a $5 \% \mathrm{CO}_{2}$-humidified atmosphere with increasing doses of 2-Fluoro-ara-AMP $(2.5,5$ and $10 \mu \mathrm{M})$ for different times $(4,8,24$ and $48 \mathrm{~h})$. At each time point, the media were separated and centrifuged to remove floating cells. Media supernatants were then submitted to solid-phase extraction using Isolute $\mathrm{C}_{18}$ columns (International Sorben Technology, Mid-Glamorgan, UK) according to the manufacturer's instructions before being analyzed by HPLC. Adherent cells were washed with phosphate buffered saline (PBS, BioWhittaker) and extracted with perchloric acid as previously described. Neutralized extracts were then used for HPLC determinations of the 5'-phosphate derivative 2-Fluoro-ara-ATP.

HPLC determinations. A $5 \mu \mathrm{m}$ Supelcosil LC-18T column (15x4.6 mm I.D.; Supelco, Bellefonte, PA, USA) protected with a guard column (Pelliguard LC-18, 20x4.6 mm I.D., pellicular packing material, $40 \mu \mathrm{m}$ particles) was used in these studies. The mobile phase used for the separation of nucleotide analogues consisted of two eluents: $0.1 \mathrm{M} \mathrm{KH}_{2} \mathrm{PO}_{4}$, $5 \mathrm{mM}$ tetrabutylammonium hydroxide (TBA) solution adjusted to $\mathrm{pH} 4.95$ by $1 \mathrm{M} \mathrm{K}_{2} \mathrm{HPO}_{4}$ (buffer A) and buffer $\mathrm{A}$ containing $30 \%(\mathrm{v} / \mathrm{v})$ of methanol (buffer B). All buffer solutions, as well as standards and sample solutions, were filtered through a $0.22 \mu \mathrm{m}$ membrane filter (Millipore, Bedford, MA). The elution conditions to obtain the chromatograms were as follows: 5 min $100 \%$ buffer A, 25 min up to $100 \%$ buffer B and hold for $5 \mathrm{~min}$. The gradient was restablished to $100 \%$ buffer $\mathrm{A}$ in $2 \mathrm{~min}$ and the initial conditions restored in $4 \mathrm{~min}$. The flow rate was $1 \mathrm{ml} / \mathrm{min}$ and the detection wavelength was $260 \mathrm{~nm}$. Analyses were performed at room temperature and quantitative measurements were carried out by injection of standard solutions of known concentration. The molar absorption value used for standard calibration of 2-Fluoro-araAMP, 2-Fluoro-ara-ADP and 2-Fluoro-ara-ATP at $260 \mathrm{~nm}$ was 15.4. The retention times under the conditions used were $19.0 \mathrm{~min}$ for 2-Fluoro-ara-A, 23,3 min for 2-Fluoro-ara-AMP, $27.4 \mathrm{~min}$ for 2-Fluoro-ara-ADP and $30.6 \mathrm{~min}$ for 2-Fluoroara-ATP.

$d C$ kinase assay. The $\mathrm{dC}$ kinase activity was measured with a radiochemical method in crude extracts employing deoxycytidine as substrate. Briefly, frozen cells were thawed and then washed with PBS. The pellet was extracted in a buffer containing $50 \mathrm{mM}$ Tris- $\mathrm{HCl}, \mathrm{pH}$ 7.6, $2 \mathrm{mM}$ dithiothreitol, $5 \mathrm{mM}$ benzidamide, $0.5 \mathrm{mM}$ phenylmethylsulfonyl fluoride, $20 \%$ glycerol and $0.5 \%$ Nonidet P40. Then the resuspended cells were frozen and thawed three times and centrifuged at $11,800 \mathrm{~g}$ for $5 \mathrm{~min}$ at $4{ }^{\circ} \mathrm{C}$ to remove cell debris. The proteins in the supernatant were used in the kinase assay, and their concentration was determined by the protein assay (Bio-Rad Laboratories, CA), according to the manufacturer's instructions. Subsequently, the activity of $300 \mu \mathrm{g}$ of protein was assayed in a reaction mixture containing $6 \mathrm{mM} \mathrm{ATP}, 6 \mathrm{mM} \mathrm{MgCl}_{2}$, $7 \mathrm{mM} \mathrm{KF}, 0.2 \%$ BSA (w/v), 0.1 M Tris- $\mathrm{HCl}, \mathrm{pH} 7.5$ and substrate $\left[{ }^{3} \mathrm{H}\right] \mathrm{dC}$ in the range $0-200 \mu \mathrm{M}$ in a total volume of $200 \mu 1$. Following the assay, samples were incubated for $1 \mathrm{~h}$ at $37^{\circ} \mathrm{C}$ and an aliquot of the reaction mixture $(100 \mu \mathrm{l})$ was spotted onto Wathman DE81 paper. Filter papers were washed 3 times in $1 \mathrm{mM}$ ammonium formate, once in water, then dehydrated in ethanol and total radioactivity was measured in a liquid scintillation B-counter, employing $3 \mathrm{ml}$ Ecoscint scintillation fluid. The radiolabeled substrates were dissolved in $0.5 \mathrm{ml}$ soluene prior to use. 
Cell cultures. An ER-positive (MCF-7) and an ER-negative (MDA-MB-435) human breast carcinoma cell line were used in the study. Both cell lines were cultured in DMEM supplemented with $2 \mathrm{mM}$ L-glutamine, $1 \%$ non-essential amino acids, $50 \mu \mathrm{g} / \mathrm{ml}$ streptomycin, $50 \mathrm{U} / \mathrm{ml}$ penicillin, $10 \mu \mathrm{g} / \mathrm{ml}$ insulin and with 10\% FBS (MCF-7) or with 5\% FBS (MDAMB-435), and grown in monolayer in a humidified atmosphere at $37^{\circ} \mathrm{C}$ with $5 \% \mathrm{CO}_{2}$. The experiments were performed with cells in the logarithmic phase of growth.

Cell survival assay. After harvesting in the logarithmic growth phase, cells were seeded in 6-well plates and allowed to attach overnight. Cells were then treated with increasing concentrations of 2-Fluoro-ara-AMP $(2.5,5$ and $10 \mu \mathrm{M})$ for different incubation times $(4,24,48,72$ and $96 \mathrm{~h})$. At $96 \mathrm{~h}$ from the beginning of treatment, cells were trypsinized and counted in a particle counter (Coulter Counter model, Coulter Electronics Limited, Luton, UK). The percentages of viable cells were determined by the trypan blue dye exclusion test. Viability always exceeded $95 \%$. Each experimental sample was run in triplicate. The results were expressed as the cell number of treated samples compared with control samples.

Flow cytometric analyses of DNA content. Cells were seeded onto $75-\mathrm{cm}^{2}$ plastic flasks and treated with 2-Fluoro-ara-AMP $2.5 \mu \mathrm{M}$. At 4, 24 and $48 \mathrm{~h}$ from the beginning of drug treatment, cells were harvested and samples of $1 \times 10^{6}$ cells were fixed in $70 \%$ ethanol. Before analysis, cells were washed in PBS and stained with a solution containing $50 \mu \mathrm{g} / \mathrm{ml}$ propidium iodide, $50 \mathrm{mg} / \mathrm{ml} \mathrm{RNase}$, and $0.05 \%$ Nonidet P40 for $30 \mathrm{~min}$ at $4{ }^{\circ} \mathrm{C}$, and then analyzed with a FACScan flow cytometer (Becton-Dickinson, Sunnyvale, CA). The cell cycle distribution was evaluated on DNA plots by CellFit software according to the SOBR model (Becton-Dickinson).

Evaluation of apoptotic cell morphology. Cells were harvested at $48 \mathrm{~h}$ after drug treatment with 2-Fluoro-ara-AMP $2.5 \mu \mathrm{M}$; adherent cells were pooled together with detached cells and then scored for nuclear morphology of apoptosis (chromatin condensation and DNA fragmentation) by labelling with a solution containing $50 \mu \mathrm{g} / \mathrm{ml}$ of propidium iodide, $50 \mathrm{mg} / \mathrm{ml}$ of RNase, and $0.05 \%$ Nonidet P40 in PBS. After staining, the slides were examined using fluorescence microscopy, and the percentage of cells with an apoptotic nuclear morphology was determined by scoring at least 500 cells in each sample.

Encapsulation of 2-Fluoro-ara-AMP in human erythrocytes. Human erythrocytes were loaded with 2-Fluoro-ara-AMP by a procedure involving hypotonic dialysis, isotonic resealing and reannealing essentially as reported (26) with some modifications. Briefly, human erythrocytes were washed in $10 \mathrm{mM}$ Hepes, $154 \mathrm{mM} \mathrm{NaCl}, 5 \mathrm{mM}$ glucose $(\mathrm{pH} 7.4$; buffer A) to remove leukocytes and platelets and were resuspended at $70 \%$ haematocrit in buffer A. Cells were then dialyzed for 90 min using a tube with a cut-off of 12-14 kDa against $50 \mathrm{vol}$ of $10 \mathrm{mM} \mathrm{NaH} \mathrm{PO}_{4}, 10 \mathrm{mM} \mathrm{NaHCO}, 20 \mathrm{mM}$ glucose (pH 7.4) containing $3 \mathrm{mM}$ glutathione and $2 \mathrm{mM}$ ATP (buffer B). The osmolarity of buffer B was $58 \mathrm{mOsm}$. After this time, $12 \mu \mathrm{mol}$ of 2-Fluoro-ara-AMP was added to each $\mathrm{ml}$ of dialyzed erythrocyte suspension. All these procedures were performed at $4^{\circ} \mathrm{C}$ under sterile conditions. Resealing of the erythrocytes was obtained by adding 0.1 vol of $5 \mathrm{mM}$ adenine, $100 \mathrm{mM}$ sodium pyruvate, $4 \mathrm{mM} \mathrm{MgCl}_{2}, 0.194 \mathrm{M}$ $\mathrm{NaCl}, 1.606 \mathrm{M} \mathrm{KCl}, 35 \mathrm{mM} \mathrm{NaH}_{2} \mathrm{PO}_{4}$ (pH 7.4) per vol of dialyzed erythrocytes and by incubating at $37^{\circ} \mathrm{C}$ for $20 \mathrm{~min}$. Resealed cells were then washed two times in buffer A and used for the studies described below.

Addition of 2-Fluoro-ara-AMP-loaded erythrocytes to MCF-7 and MDA-MB-435 cells. To evaluate the ability of 2-Fluoroara-AMP-loaded erythrocytes to release 2-Fluoro-ara-A in culture medium and to determine its uptake by cancer cell lines, loaded erythrocytes at $2 \%$ haematocrit were incubated, in the absence or in the presence of MCF-7 and MDA-MB-435 cells in 6-well plates at $37^{\circ} \mathrm{C}$ in a $5 \% \mathrm{CO}_{2}$ atmosphere. At different times (4, 24, 48, 72 and $96 \mathrm{~h})$, erythrocyte suspensions were removed, supernatants were separated and processed for 2-Fluoro-ara-A determination by HPLC analysis, as already described. To investigate the cytotoxic activity of 2-Fluoroara-AMP-loaded erythrocytes, cells were incubated with 2Fluoro-ara-AMP-loaded erythrocytes at $2 \% \mathrm{Ht}$ for different times $(4,24,48,72$ and $96 \mathrm{~h})$. At $96 \mathrm{~h}$ from the beginning of treatment, cells were trypsinized and counted in a particle counter (Coulter Counter model). The percentages of viable cells were determined by the trypan blue dye exclusion test. Viability always exceeded $95 \%$. Each experimental sample was run in triplicate. The results were expressed as the cell number of treated samples compared with control unloaded erythrocytes (UL RBC), that is, erythrocytes submitted to loading procedure without adding 2-Fluoro-ara-AMP.

Comparison of P53 and STAT1 expression before and after incubation with 2-Fluoro-ara AMP. Cells cultures were washed twice with PBS pH 7.4 (phosphate buffered saline) and successively lysed in Lyses Buffer $50 \mathrm{mM}$ Tris- $\mathrm{HCl}$ pH 7.8, 2\% (w/v) sodium dodecyl sulfate (SDS), 5 mM EDTA (ethylenediaminetetraacetic acid) $5 \mathrm{mM}, 109 \mathrm{mM}$ NEM (Nethylmaleimide) in presence of protease inhibitors: $2 \mathrm{mg} / \mathrm{ml}$ leupeptin, $2 \mathrm{mg} / \mathrm{ml}$ pepstatin, $4 \mathrm{mM}$ AEBSF [4-(2-Aminoethyl) benzenesulphonyl fluoride] and $1 \mathrm{mM}$ PMSF (Phenylmethylsulphonylfluoride) and phosphatase inhibitors: $1 \mathrm{mM}$ sodium orthovanadate and $1 \mathrm{mM}$ of sodium fluoride. Whole cell lysates were boiled immediately for $5 \mathrm{~min}$ and centrifuged at $6,000 \mathrm{x} \mathrm{g}$ for $13 \mathrm{~min}$. The protein concentration of cell extracts was determined by the Lowry protein assay (27). Thirty micrograms of cell extracts were resolved on $7.5 \%$ SDS-PAGE (28) and transferred by electroblotting on Hybond-C Extra nitrocellulose membrane (Amersham Pharmacia Biotech, Italy) for $60 \mathrm{~min}$ at $100 \mathrm{~V}$ with a Bio-Rad transblot (Bio-Rad laboratory, Germany) (29). For the immunoassay, membranes were treated with Blocking Solution: 5\% (w/v) dry milk dissolved in TBS (150 mM NaCl, $50 \mathrm{mM}$ Tris $\mathrm{pH}$ 7.5) maintained for $1 \mathrm{~h}$ at room temperature. The specific antibodies were incubated in diluted blocking solution overnight at $4{ }^{\circ} \mathrm{C}$. The antibody utilized for p53 determination was a polyclonal antibody anti-p53 that recognizes the wild-type and mutated form of the protein (Santa Cruz Biotechnology Inc., Santa Cruz, CA). Antibodies utilized in the different Western immunoblottings were the following: polyclonal anti p-Tyr701-STAT1 (Cell Signaling), polyclonal anti STAT1 


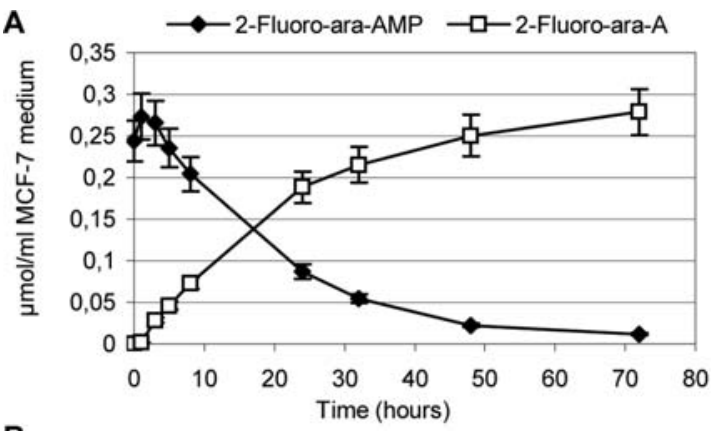

B

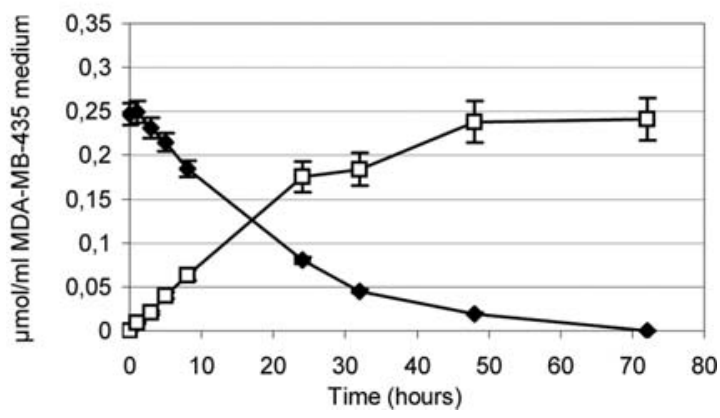

Figure 1. Pharmacokinetics of 2-Fluoro-ara-AMP in culture media. The MCF-7 and MDA-MB-435 culture media were incubated in the presence of $0.3 \mathrm{mM}$ 2-Fluoro-ara-AMP at $37^{\circ} \mathrm{C}$ for $72 \mathrm{~h}$. At different time intervals $(0,1,3,5,8,24,32,48$ and 72 h) 2-Fluoro-ara-AMP and the corresponding dephosphorylated derivative were determined by high-performance liquid chromatography (HPLC) of perchloric acid extracts. Results are the mean value $( \pm \mathrm{SD})$ of 3 different experiments.

(Santa Cruz Biotechnology Inc.) and polyclonal anti-Actin (Sigma Chemical Inc., Italy). The immune complexes were detected with horseradish peroxidase-conjugated goat antirabbit and horseradish peroxidase-conjugated goat anti-mouse antiserum (Bio-Rad laboratory, Germany) and followed by enhanced chemiluminescence reaction (ECL, Amersham Pharmacia Biotech, Italy). Quantitative analysis was performed by a Chemi Doc System and Quantity One Program System (Bio-Rad laboratory).

Other determinations. Erythrocyte counts and haematological parameters (haematocrit and mean cell volume) were determined by cell counter ABX Micros 60 (Horiba Medical Italia).
All results reported in this paper are mean \pm SD of at least three different determinations in duplicate.

\section{Results}

MCF-7 and MDA-MB-435 media dephosphorylate 2-Fluoroara-AMP to $F$-ara-A. Since the first-step in the metabolism of 2-Fluoro-ara-AMP is its dephosphorylation to the nucleoside F-ara-A, the ability of MCF-7 and MDA-MB-435 culture media to dephosphorylate 2-Fluoro-ara-AMP to its diffusible form, 2-Fluoro-ara-A, was evaluated. As shown in Fig. 1A and $\mathrm{B}$, both cell media were found to remove the phosphate group at the same rate: $50 \%$ of 2-Fluoro-ara-AMP was already dephosphorylated after approximately $20 \mathrm{~min}$, and completely transformed into 2-Fluoro-ara-A after approximately $1 \mathrm{~h}$. These results are due to the presence of FBS (fetal bovine serum) in culture media that possesses the 5'-nucleotidase activity necessary to convert the prodrug into the diffusible form that can be internalized by the cells. In fact, similar results have been obtained by incubating 2-Fluoro-ara-AMP in human plasma (data not shown).

MCF-7 and MDA-MB-435 cell lines metabolize 2-Fluoroara-A to 2-Fluoro-ara-ATP. Like other nucleoside analogues, 2-Fluoro-ara-A requires phosphorylation to its tri-phosphorylated form to show cytotoxic and therapeutic activity. The accumulation of 2-Fluoro-ara-ATP in both cell lines incubated for different times (4, 8, 24 and $48 \mathrm{~h}$ ) with different 2-Fluoroara-AMP concentrations $(2.5,5.0$ and $10 \mu \mathrm{M})$ was therefore evaluated. The data obtained (Fig. 2A) show that 2-Fluoroara-ATP could be detected in MCF-7 cells only after $24 \mathrm{~h}$ of incubation and that its accumulation was concentration and time-dependent, while in MDA-MB-435 cells, the triphosphorylated form was already present after $4 \mathrm{~h}$ of incubation and its accumulation appeared independent on drug concentrations and the drug exposure times tested (Fig. 2B). This result is in accordance with the higher $\mathrm{V}_{\max } / \mathrm{k}_{\mathrm{m}}$ values obtained for MDA-MB-435 compared to MCF-7 cell line (Table I). However, at $48 \mathrm{~h}$, the same 2-Fluoro-ara-ATP concentrations in both lines were observed. The low monophosphate and diphosphate levels in cells (data not shown) confirms that phosphorylation by deoxycytidine kinase is rate-limiting for 2-Fluoro-ara-ATP formation.

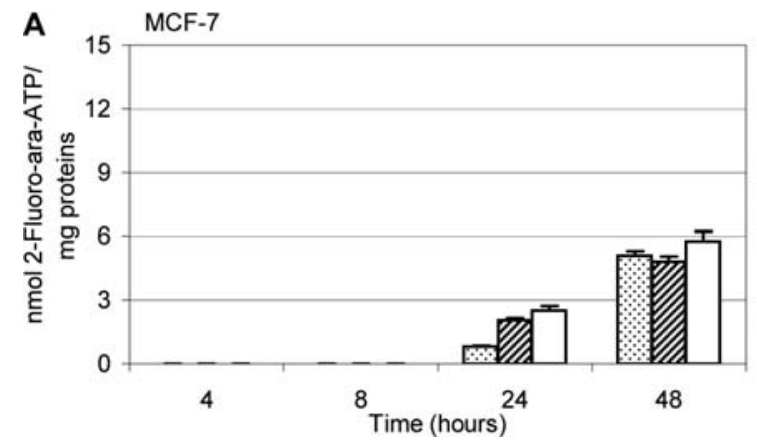

B MDA-MB-435 2,5 $\mu$ M $5 \mu \mathrm{M} \quad \square 10 \mu \mathrm{M}$

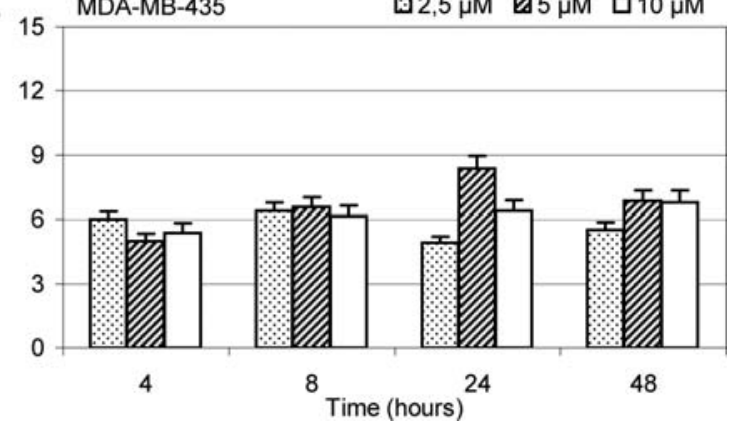

Figure 2. Metabolism of 2-Fluoro-ara-AMP in MCF-7 and MDA-MB-435 cell lines. MCF-7 and MDA-MB-435 cells were incubated at $37^{\circ} \mathrm{C}$ with increasing doses of 2-Fluoro-ara-AMP $(2.5,5$ and $10 \mu \mathrm{M})$ for different times $(4,8,24$ and $48 \mathrm{~h})$. At each time from the beginning of treatment, neutralized extracts of adherent cells were used for HPLC determinations of 2-Fluoro-ara-ATP. Results are the mean value $( \pm \mathrm{SD})$ of 3 different experiments. 
A

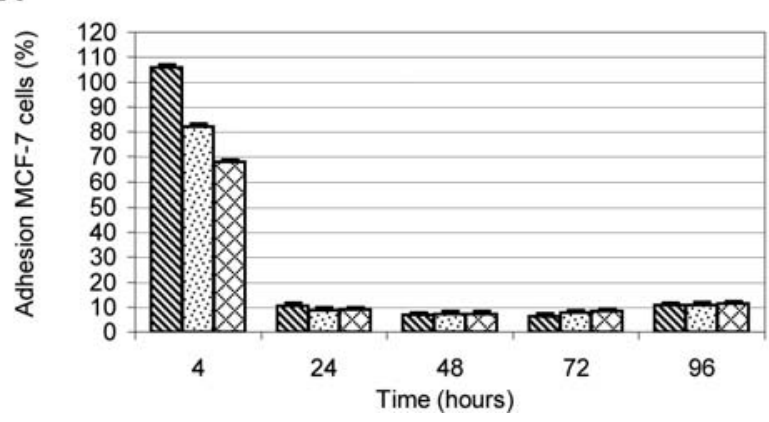

B

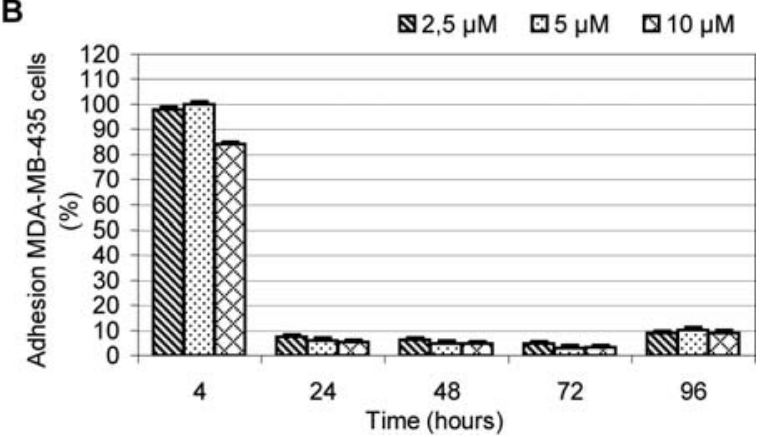

Figure 3. Cytotoxicity of free 2-Fluoro-ara-AMP. Cells were treated with increasing concentrations of 2-Fluoro-ara-AMP (2.5, 5, $10 \mu \mathrm{M})$ for different incubation times $(4,24,48,72$ and $96 \mathrm{~h})$. At $96 \mathrm{~h}$ from the beginning of treatment, cells were trypsinized and counted and the percentages of viable cells determined. Each experimental sample was run in triplicate. The results were expressed as the cell number of treated samples compared with control samples.

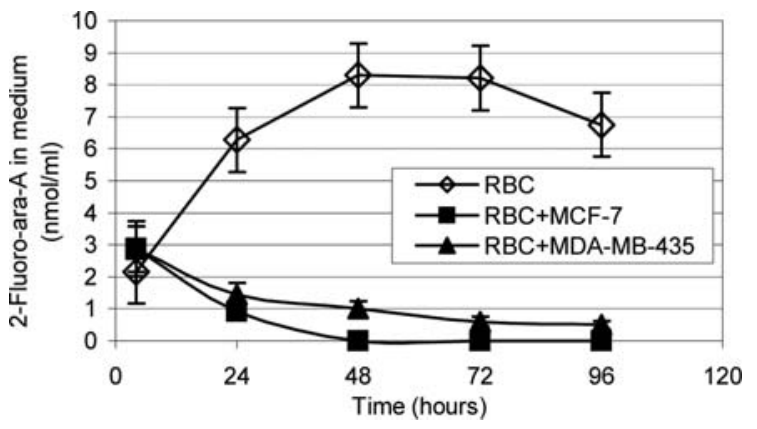

Figure 4. Release of 2-Fluoro-ara-A from 2-Fluoro-ara-AMP-loaded erythrocytes and its uptake by cancer cell lines. Loaded erythrocytes at $2 \%$ haematocrit were incubated, in the absence or in the presence of MCF-7 and MDA-MB-435 cells. At different times (0, 24, 48, 72 and 96 h), erythrocyte suspensions and adhese cells were processed for 2-Fluoro-ara-A determination by HPLC analysis. Results are the mean value $( \pm \mathrm{SD})$ of 3 different experiments.

Table I. Determination of enzymatic activity of dC kinase in MCF-7 and MDA-MB-435 cell lines.

\begin{tabular}{lccc}
\hline & $\begin{array}{c}\mathrm{Km} \\
(\mathrm{mM})\end{array}$ & $\begin{array}{c}\text { Vmax } \\
(\mathrm{nmol} / \mathrm{min} / \mathrm{mg} \text { protein })\end{array}$ & $\mathrm{Vmax} / \mathrm{km}$ \\
\hline MCF-7 & 0.318 & 0.0995 & 0.313 \\
MDA-MB-435 & 0.088 & 0.0723 & 0.822 \\
\hline
\end{tabular}

The $\mathrm{dC}$ kinase activity was measured with a radiochemical method in crude extracts employing deoxycytidine as substrate. Samples were incubated for $1 \mathrm{~h}$ at $37^{\circ} \mathrm{C}$ and an aliquot of the reaction mixture was spotted onto Wathman DE81 paper. Filter papers were washed, dehydrated in ethanol and total radioactivity was measured.

Antiproliferative activity of 2-Fluoro-ara-AMP. The antiproliferative effect of 2-Fluoro-ara-AMP was studied in hormone-responsive, low-invasive MCF-7 cell line and hormone-insensitive, highly invasive MDA-MB-435 cell line exposed to increasing concentrations of the drug (from 2.5 to $10 \mu \mathrm{M}$ ) for different exposure times (from 4 to $96 \mathrm{~h}$ ). In MCF-7 cells, a dose-dependent, although modest, inhibition
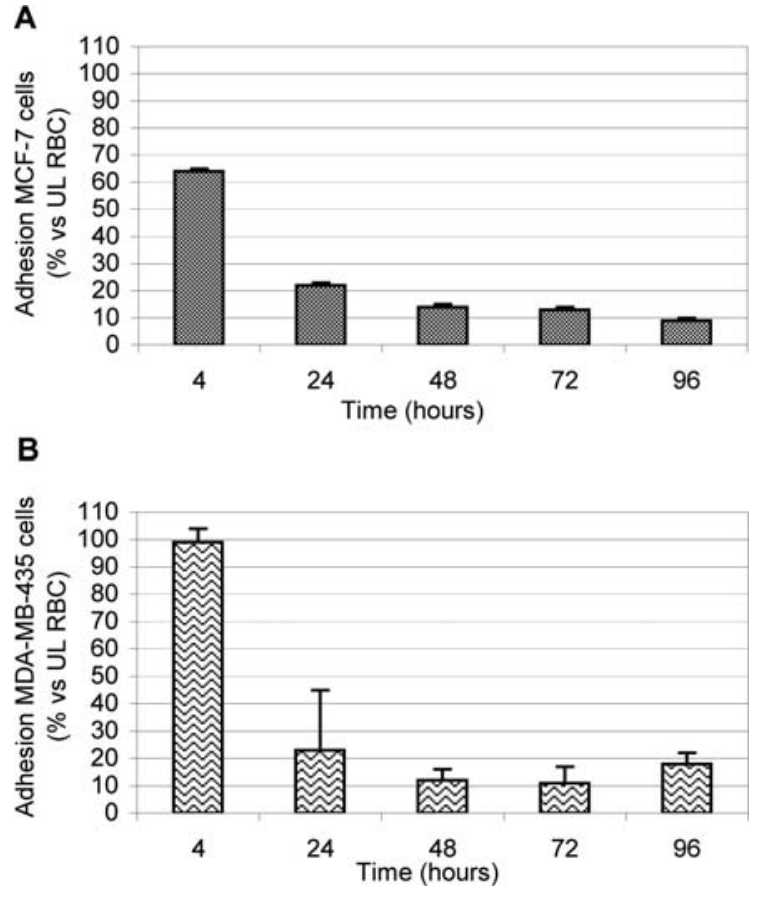

Figure 5. Antiproliferative effect of 2-Fluoro-ara-AMP-loaded erythrocytes. Cells were incubated with 2-Fluoro-ara-AMP-loaded erythrocytes at $2 \% \mathrm{Ht}$ for different times $(4,24,48,72$ and $96 \mathrm{~h})$. The percentages of viable cells were all determined at 96 hours by the trypan blue dye exclusion test. Each experimental sample was run in triplicate. The results were expressed as the cell number of treated samples compared with control unloaded erythrocytes (UL RBC).

of cell number was already evident after $4 \mathrm{~h}$ of treatment. After a $24 \mathrm{~h}$ exposure to 2-Fluoro-ara-AMP, an almost complete abrogation of growth was observed in these cells ( $\sim 90 \%$ inhibition when compared to controls) independent of drug concentration, and the extent of inhibition remained stable until the last time point considered (96 h) (Fig. 3A). As far as MDA-MB-435 cells are concerned, a negligible effect on cell growth was found following a 4-h exposure to the drug. Conversely, longer drug exposure times caused a marked inhibition of cell proliferation, which was independent of drug concentration and superimposable to that observed in MCF-7 cells (Fig. 3B). 
A
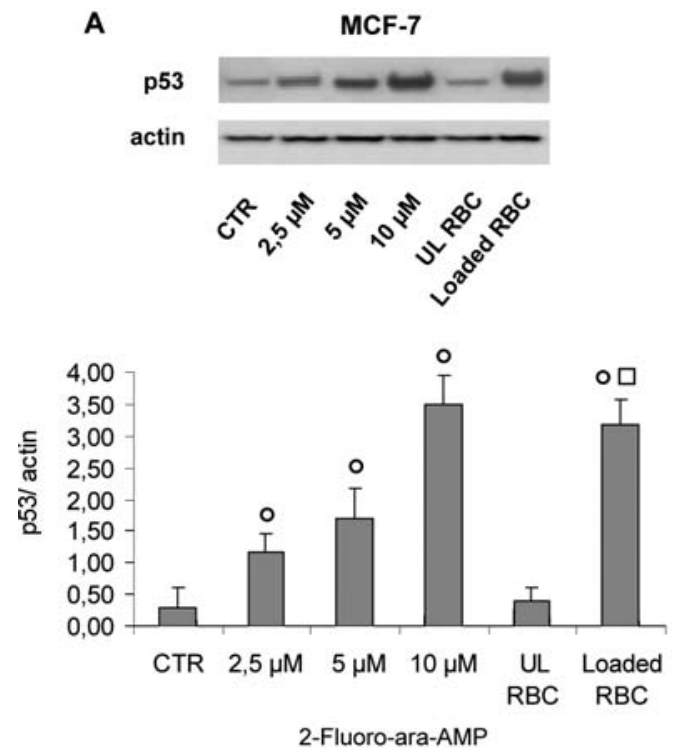

B

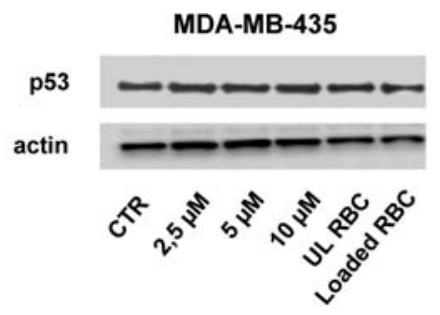

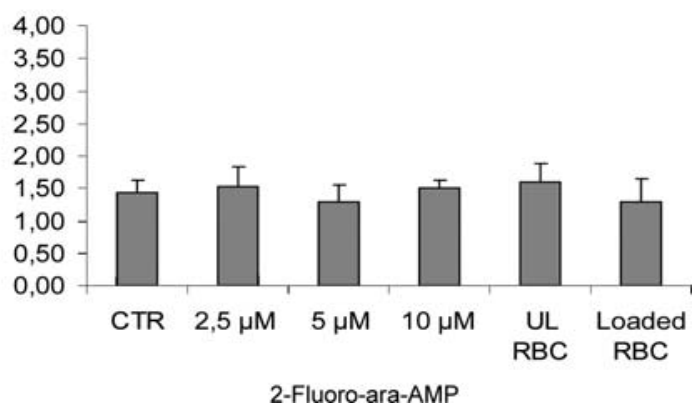

Figure 6. (A) Expression of the protein p53 in MCF-7 cells and the effect of 2-Fluoro-ara-AMP on the p53. Upper left: Western blot analysis of p53 and actin levels in MCF-7 cells treated or untreated with different amounts of free 2-Fluoro-ara-AMP or encapsulated in RBC. Lower left: Densitometry value of p53 normalized on actin levels (p53/actin). Results are the mean value $( \pm \mathrm{SD})$ of 3 different experiments. ${ }^{\circ} \mathrm{p} 53$, different from control cells ( $\left.<<0.01\right)$; ${ }^{\square} \mathrm{p} 53$, different from cells treated with UL RBC (p<0.01). (B) Expression of protein 553 in MDA-MB-435 cells and the effect of 2-Fluoro-ara-AMP on the p53. Upper right: Western blot analysis of p53 and actin levels in MDA-MB-435 cells treated or untreated with different amounts of free 2-Fluoro-ara-AMP or encapsulated in RBC. Lower right: Densitometric value of p53 normalized on actin levels (p53/actin). Differences between the various samples were evaluated and were not significant. Results are the mean value $( \pm \mathrm{SD})$ of 3 different experiments.

Table II. Flow cytometric analyses of DNA content.

Time

Samples
$4 \mathrm{~h}$

$\mathrm{Ct} \quad$ 2-Fluoro-ara-AMP
$(2.5 \mu \mathrm{M})$

$24 \mathrm{~h}$

Ct 2-Fluoro-ara-AMP
$(2.5 \mu \mathrm{M})$
$48 \mathrm{~h}$

2t-Fluoro-ara-AMP
$(2.5 \mu \mathrm{M})$

\begin{tabular}{lllllll}
\hline MCF-7 & & & & & & \\
G1 & $42 \%$ & $44 \%$ & $53 \%$ & $62 \%$ & $60 \%$ & $69 \%$ \\
S & $44 \%$ & $43 \%$ & $37 \%$ & $27 \%$ & $32 \%$ & $21 \%$ \\
G2 & $14 \%$ & $13 \%$ & $10 \%$ & $11 \%$ & $8 \%$ & $10 \%$ \\
MDA-MB-435 & & & & & & \\
G1 & $41 \%$ & $42 \%$ & $52 \%$ & $50 \%$ & $46 \%$ & $46 \%$ \\
S & $37 \%$ & $36 \%$ & $29 \%$ & $35 \%$ & $34 \%$ & $38 \%$ \\
G2 & $22 \%$ & $22 \%$ & $19 \%$ & $15 \%$ & $20 \%$ & $16 \%$ \\
\hline
\end{tabular}

Cells were treated with 2-Fluoro-ara-AMP $2.5 \mu \mathrm{M}$. At 4, 24 and $48 \mathrm{~h}$ from the beginning of drug treatment, samples of $1 \times 10^{6}$ of cells were fixed in ethanol, stained with propidium iodide and then analyzed with a FACScan flow cytometer.

Flow cytometric analyses of DNA content and evaluation of apoptotic cell morphology. To assess the effects induced by the drug on the cell cycle, we exposed the two breast cancer cell lines to $2.5 \mu \mathrm{M}$ 2-Fluoro-ara-AMP for different intervals (from 4 to $48 \mathrm{~h}$ ). Flow cytometry profiles of nuclear DNA content in the MCF-7 cells revealed that the drug was able to induce an increase in the percentage of cells in the $G_{1}$ compartment and a concomitant reduction in the percentage of S-phase cells (Table II). Conversely, in MDA-MB-435 cells, treatment failed to interfere with the progression of cells throughout the cell cycle (Table II), thus suggesting that, at least at this relatively low concentration, 2-Fluoro-ara-AMP suppressed the growth of MDA-MB-435 cells without inducing a specific block of the cell cycle. Moreover, flow cytometric analyses conducted in both MCF-7 and MDA-MB-435 cells after drug treatment did not show the presence of a detectable pre- $G_{1}$ apoptotic cell population. Accordingly, fluorescence microscopy analysis did not reveal the presence of cells with 
A

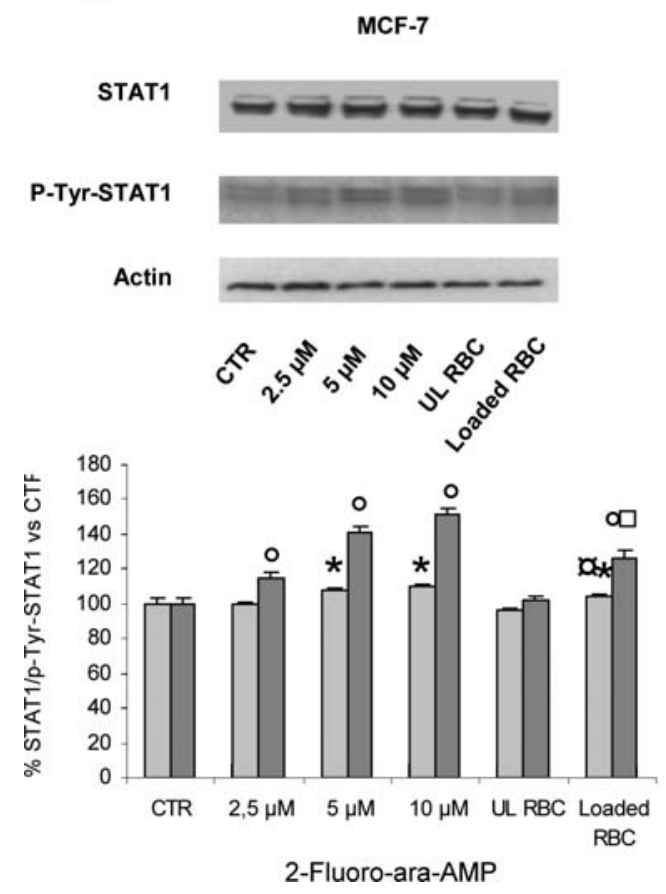

B

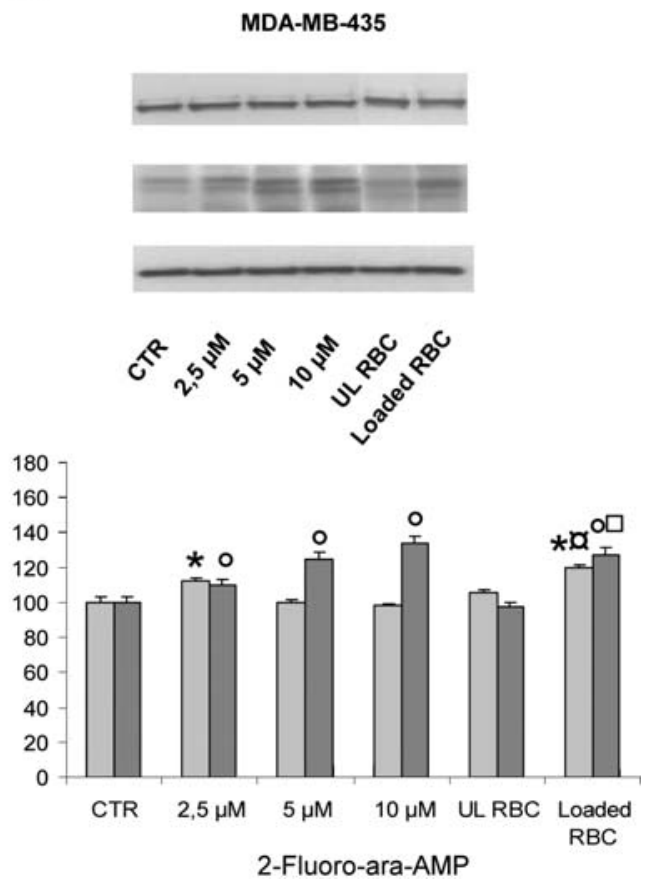

Figure 7. (A) Activation of Signal Transducer and activator of transcription type 1 (STAT1) in MCF-7 cells and the effect of 2-Fluoro-ara-AMP on the STAT1/p-STAT1 pathway. Upper left: Western blot analysis of STAT1 and p-Tyr-STAT1 and actin levels in MCF-7 cells treated or untreated with different amounts of free 2-Fluoro-ara-AMP or encapsulated in RBC. Lower left: Quantitative analyses of STAT1 and p-Tyr-STAT1 normalized to the amount of actin and expressed as a percentage compared with control cells. Results are the mean value $( \pm \mathrm{SD})$ of 3 different experiments. * STAT1, different from control cells

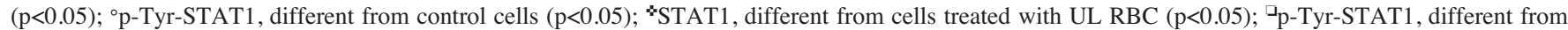
cells treated with UL RBC (p<0.05). (B) Activation of Signal Transducer and activator of transcription type 1 (STAT1) in MDA-MB-435 cells and the effect of 2-Fluoro-ara-AMP on the STAT1/p-STAT1 pathway. Upper right: Western blot analysis of STAT1 and p-Tyr-STAT1 and actin levels in MDA-MB-435 cells treated or untreated with different amounts of free 2-Fluoro-ara-AMP or encapsulated in RBC. Lower right: Quantitative analyses of STAT1 and p-TyrSTAT1 normalized to the amount of actin and expressed as a percentage compared with control cells. Results are the mean value ( \pm SD) of 3 different experiments. *STAT-1, different from control cells ( $<<0.05)$; ${ }^{\circ}$-Tyr-STAT1, different from control cells $(\mathrm{p}<0.05)$; ${ }^{*} \mathrm{STAT} 1$, different from cells treated with

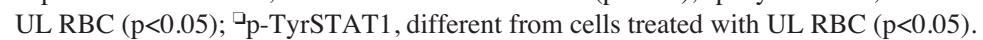

the nuclear morphology of apoptosis (in terms of chromatin condensation and DNA fragmentation) after labelling of drugtreated cultures with propidium iodide (not shown).

2-Fluoro-ara-AMP-loaded erythrocytes release 2-Fluoro$\operatorname{ara}-A$. To provide potential advantages in terms of both efficacy and reduction of toxicity, 2-Fluoro-ara-AMP was encapsulated in human erythrocytes which can thus provide as slow-delivery system for 2-Fluoro-ara-A as previously suggested (30). The procedure of hypotonic dialysis and isotonic resealing allowed the internalization of $0.735 \pm 0.22 \mu \mathrm{mol} / \mathrm{ml}$ erythrocytes with an average percentage of encapsulation of $20 \%$ of 2-Fluoro-ara-AMP and a cell recovery higher than $70 \%$. Encapsulation of 2Fluoro-ara-AMP did not result in any appreciable alteration of erythrocyte morphology and metabolism (data not shown). The ability of 2-Fluoro-ara-AMP-loaded erythrocytes to release 2-Fluoro-ara-A in cell media and its disappearance from media due to the uptake by MCF-7 and MDA-MB-435 cells was evaluated. The results obtained (Fig. 4, empty symbols) show that 2-Fluoro-ara-AMP loaded erythrocytes release 2-Fluoro-ara-A in a time-dependent manner reaching the maximum concentration in culture media $48 \mathrm{~h}$ after the beginning of incubation. In the presence of MCF-7 and MDA-MB-435 cell lines (Fig. 4, full symbols) 2-Fluoro-ara-A is rapidly removed from culture media; the internalization of the compound appeared faster for MCF-7 cells (up to its complete disappearance from the medium after just $48 \mathrm{~h}$ ) compared to MDA-MB-435 cells, where low levels of diffusible drug were still present at last time tested (96 h).

Antiproliferative effect of 2-Fluoro-ara-AMP-loaded erythrocytes. Breast cancer cells were exposed to 2-Fluoro-ara-AMPloaded erythrocytes to evaluate the in vitro efficiency of the payload release (2-Fluoro-ara-A) and the consequent cytotoxic effect. Specifically, for cytotoxicity experiments, cells were incubated with 2-Fluoro-ara-AMP-loaded red blood cells for different intervals (ranging from 4 to $96 \mathrm{~h}$ ) and the growth inhibitory activity exerted by the released drug was assessed by evaluating the percentage of viable, adherent cells. In both cell lines, an antiproliferative effect of 2-Fluoro-ara-A released from loaded erythrocytes could be detected (Fig. 5); however, it is noteworthy that in MCF-7 cells, the cytotoxic effect was already appreciable after a 4-h exposure while no effect at this time was registered in MDA-MB-435 cells, confirming what was previously observed with the free drug at the same exposure time (Fig. 1); following longer treatment periods, a similar, remarkable inhibition of MCF-7 and MDA-MB-435 cell growth was observed, with a reduction in cell number around $90 \%$ after $48 \mathrm{~h}$ of drug exposure. 
Effect of 2-Fluoro-ara-AMP on 553 and STAT1. The expression levels of p53 in MCF-7 and MDA-MB-435 treated with free and RBC loaded 2-Fluoro-ara-AMP were evaluated: the results obtained in MCF-7 cells line (Fig. 6A) show a markedly enhanced expression of p53 after drug treatment: in fact, the immunoreactive band increases in a concentration-dependent manner, reaching values higher than 10-fold when compared to control cells both in cells treated with $10 \mu \mathrm{M}$ of 2-Fluoroara-AMP and with 2-Fluoro-ara-AMP-loaded RBC, and values higher than 9-fold respect to cells treated with UL RBC in cells treated with 2-Fluoro-ara-AMP-loaded RBC. On the contrary, the same assay carried out on MDA-MB-435 (a p53 mutated cell line), shows an equal level of p53 in all experimental conditions (Fig. 6B) as expected (31).

Since convergent studies suggest that p53 and STAT1 cooperate in the induction of cell death and that 2-Fluoro-araAMP is activator of STAT1 in p53 expressing cells (32), the expression levels of STAT1 in MCF-7 and MDA-MB-435 treated with free and RBC loaded 2-Fluoro-ara-AMP were evaluated. Fig. 7 shows results obtained by Western blot analysis of STAT1 and p-Tyr-STAT1 levels on total cell extracts of MCF-7 (A) and MDA-MB-435 (B) cell lines. STAT1 exists as 2 protein products: the $91-\mathrm{kDa}(\alpha)$ and the $84-\mathrm{kDa}(ß)$ isoforms. Both proteins contain the $701 \mathrm{Tyr}$ residue, the phosphorylation of which is required for activation, dimerization and nuclear translocation (33-35). To evaluate the effect of 2-Fluoro-ara-AMP on the STAT1 pathway, the MCF-7 and MDA-MB-435 cells were exposed to 2-Fluoroara-AMP 2.5, 5.0 and $10 \mu \mathrm{M}$ and 2-Fluoro-ara-AMP-loaded erythrocytes for $24 \mathrm{~h}$. As shown in Fig. 7A, 2-Fluoro-araAMP induces only a slight increase in the levels of STAT1 in MCF-7 cells, but a substantial increase in p-Tyr-STAT1 indicating activation of the pathway. In MCF-7 treated with different concentrations of free 2-Fluoro-ara-AMP, the levels of p-Tyr-STAT1 increase in a dose-dependent manner, reaching values $50 \%$ higher than in control ones. In cells treated with 2-Fluoro-ara-AMP-loaded erythrocytes, the pTyr-STAT1 levels reach densitometric values $26 \%$ higher than in control and UL treated cells. A similar trend was obtained in the MDA-MB-435 cells (Fig. 7B), even if the STAT1 protein is poorly represented in this cell line and thus the Western blot analysis was performed on a larger amount of cell extract compared to MCF-7 cells. Although in this case the immuno-reactive bands of STAT1 tend to be equal to those of control cells, the increment in p-Tyr-STAT1 levels in a dose-dependent manner demonstrates the activation of the STAT1 pathway also in the MDA-MB-435 cells line, reaching values up to $34 \%$ respect to control cells. Furthermore, 2-Fluoro-ara-AMP-loaded erythrocytes increment the p-Tyr-STAT1 levels by approximately $28 \%$ compared to control and UL treated cells, demonstrating the efficacy of the encapsulated drug in this case as well.

\section{Discussion}

Breast cancer is the most common type of tumor in women in Western countries. Although much progress has been made in its treatment, there are still a considerable number of patients for which conventional chemotherapy is ineffective and consequently new approaches need to be developed. Thus, the aim of this study was to evaluate the cytotoxic effects of 2-Fluoroara-AMP against two human breast cancer cell lines having a different estrogen receptor (ER) expression profile: the ERpositive MCF-7 and the ER-negative MDA-MB-435 cell lines. Even if this purine analogue is currently used for the treatment of acute and indolent haematologic malignancies (that include tumors of myeloid and lymphoid lineage), previous studies in which 2-Fluoro-ara-AMP was tested against human tumor specimens of different histological origin, also showed a significant antitumor activity against breast cancer $(36,37)$, leading us to further investigate its cytotoxic effects in breast cancer cell lines. Since the cytotoxic capacity of 2-Fluoroara-AMP is directly linked to its ability to be taken up by cells and phosphorylated to its triphosphate metabolite, we first demonstrated that MCF-7 and MDA-MB-435 cell culture media were able to convert the prodrug 2-Fluoro-ara-AMP to its diffusible antimetabolite Fluoro-ara- $\mathrm{A}\left(\mathrm{t}_{1 / 2}=20 \mathrm{~min}\right)$ and that in both cell lines the active triphosphated form, 2-Fluoroara-ATP, was accumulated, even if at different rates as justified by the different catalytic efficiency of $\mathrm{dC}$ kinase in the two cell lines (Table I). However, though undetectable levels of 2-Fluoro-ara-ATP were observed in MCF-7 cells during the first treatment times considered ( 4 and $8 \mathrm{~h}$ ), reaching only at the last time ( $48 \mathrm{~h}$ ) superimposable levels with MDA-MB-435 cells, similar antiproliferative effects of 2-Fluoro-ara-AMP in the two cell lines were obtained causing an almost complete abrogation of growth after just $24 \mathrm{~h}$ of drug exposure at all the tested doses $(2.5,5.0$ and $10 \mu \mathrm{M})$. This seems to indicate that MCF-7 cells are more sensitive than MDA-MB-435 cells to the treatment.

At present, 2-Fluoro-ara-AMP is administered to patients with lymphoproliferative malignancies at the standard dose of $25-30 \mathrm{mg} / \mathrm{m}^{2} /$ day, given over $30 \mathrm{~min}$ for 5 days every 28 days (for different lengths of time), that leads to a plasma 2-Fluoro-ara-A concentration of about $3 \mu \mathrm{mol} / 1(\mu \mathrm{M})$ at the end of each infusion (12); since this concentration resulted efficacious in the inhibition of MCF-7 and MDA-MB-435 cell growth, it would be reasonable to assume that a similar therapeutic protocol could also be used in patients with breast cancer. Actually, this therapeutic approach has already been evaluated in a phase II clinical trial (38) where 2-Fluoro-araAMP provided minimal efficacy in the treatment of heavily pretreated patients with advanced refractory breast cancer. However, no data exist regarding drug efficacy in patients with a less severe clinical situation where a greater efficacy of the antineoplastic agent cannot be excluded. In addition, it is acceptable that by modifying the pharmacokinetic profile of the 2-Fluoro-ara-AMP, an increase in its efficacy and a decrease in its toxicity could be reached. To this end, since the ability of 2-Fluoro-ara-AMP-loaded red blood cells to act as bioreactors to slowly release 2-Fluoro-ara-A is known (25), the antiproliferative activity of these engineered erythrocytes in MCF-7 and MDA-MB-435 cells was evaluated. 2-Fluoroara-A was successfully released in culture media in a timedependent manner $[12.5 \mathrm{nmol} / \mathrm{h}$ per $\mathrm{ml}$ erythrocytes, confirming results previously obtained (25)] and a cytotoxic activity similar to that shown with the free drug treatment was registered. These results suggest the possibility of administering 2-Fluoro-ara-AMP to patients with breast cancer by using autologous erythrocytes as a system to slowly deliver 
2-Fluoro-ara-A in circulation. An apparatus called 'Red Cell Loader', which allows the encapsulation of drugs in human erythrocytes for clinical purposes, is available (37) and it has already been used in patients with inflammatory diseases to release in the circulation the glucocorticoid analogue Dexamethasone in several clinical trials (38-42). Successively, in the attempt to better characterize the mechanisms by which 2-Fluoro-ara-AMP causes cytotoxicity in breast cancer cell lines, the effects induced by the drug on the cell cycle were investigated. As revealed by the analysis of DNA content, 2-Fluoro-ara-AMP was able to produce a specific block in the progression of the cell cycle only in the MCF-7 cells, but did not cause apoptosis in this cell line [as expected since MCF-7 are notably caspase-3 deficient (43-45)] nor in the MDA-MB-435 cells, leading us to further investigate the mechanisms involved in the antiproliferative effect of the antineoplastic drug. In particular, since 2-Fluoro-ara-AMP is a potent activator of $\mathrm{p} 53$, a transcription factor able to block the cell cycle (18), p53 expression was evaluated both in MCF-7 and in MDA-MB-435 cells. A remarkable overexpression of $\mathrm{p} 53$ was observed in MCF-7 cell line following 24 h-treatment both with free and with the encapsulated drug; in particular, the treatment with 2-Fluoro-ara-AMP-loaded RBC caused an increase in $\mathrm{p} 53$ protein into the range of the values obtained with the higher concentrations (5.0 and $10 \mu \mathrm{M})$ of the free drug as expected by the kinetic release of 2-Fluoro-ara-A from erythrocytes (Fig. 4). Otherwise, no increase in p53 expression was obtained in MDA-MB-435 cells, notoriously mutant p53 cells lacking transcriptional activity (30). Here, p53 levels were comparable to those registered in untreated control cells which expressed elevated basal levels of the mutant protein as previously reported (30). Moreover, since it is known that: i) the cytotoxic activity of the p53 inducer is increased by STAT1 transcriptional activation (46), ii) STAT1 activation is implicated as a tumor suppressor (47), iii) STAT1 activation induced by the genotoxic drug depends on p53 protein but not on its transcriptional activity (31), activation of the STAT1 pathway on ER ${ }^{+}$ and $\mathrm{ER}^{-}$cancer cell lines was investigated. Activation significantly occurred both in MCF-7 and in MDA-MB-435 cells and the treatment with 2-Fluoro-ara-AMP-loaded RBC again resulted in an increase of p-Tyr-STAT1 into the range of the values obtained with the higher concentrations of the free drug. Taken together, these results seem to suggest two different mechanisms of action for the cell lines: in MCF-7 cells, the antiproliferative action of the drug could be explained by a p53-dependent pathway of STAT1 which transcriptionally up-regulates p21, a target gene involved in cell cycle arrest without induction of the apoptotic program $(31,48)$ while in MDA-MB-435 cells, the activation of the STAT1 pathway alone could be sufficient to mediate growth inhibition, overcoming the resistance of p53-mutated cells to the genotoxic agent (31). Otherwise, the same mechanism proposed for MCF-7 cells could be responsible for the cytotoxic activity of 2-Fluoro-ara-AMP in MDA-MB-435 cells in the case that the simple presence of $\mathrm{p} 53$ protein, and not its transcriptional activity, is sufficient for STAT1 activation, as suggested by Youlyouz-Marfak et al (31).

In summary, our data demonstrate that the genotoxic agent 2-Fluoro-ara-AMP shows antiproliferative activity against both the ER ${ }^{+}$MCF-7 and the ER- MDA-MB-435 cells and that, when encapsulated into erythrocytes, it is slowly and constantly released in its diffusible form, 2-Fluoro-ara-A, with a cytotoxic activity superimposable to that obtained with the free drug. Clinical trials (Phase I and II) could be useful in evaluating the potentiality of the new pharmacokinetic profile in reducing drug toxicity and improving drug efficacy. Moreover, preliminary studies carried out to elucidate the pathways implicated in the drug cytotoxicity seem to indicate the involvement of both p53 and STAT1 proteins. Further investigations are however required to confirm our hypothesis.

\section{Acknowledgements}

We thank Schering S.p.A. for providing 2-Fluoro-ara-AMP used in these studies. This study was supported by FIRB funds (PNR 2001-2003, Red blood cells as drug carriers, RBNE01TBTR).

\section{References}

1. Keating MJ, Kantarjian H, Talpaz M, Redman J, Koller C, Barlogie B, Velasquez W, Plunkett W, Freireich EJ and McCredie KB: Fludarabine: a new agent with major activity against chronic lymphocytic leukemia. Blood 74: 19-25, 1989.

2. Warrell RP Jr and Berman E: Phase I and II study of fludarabine phosphate in leukemia: therapeutic efficacy with delayed central nervous system toxicity. J Clin Oncol 4: 74-79, 1986.

3. Boogaerts MA: Oral fludarabine therapy in chronic lymphocytic leukemia-increased convenience. Hematol J 5 (Suppl. 1): S31-S37, 2004.

4. Chun HG, Leyland-Jones B and Cheson BD: Fludarabine phosphate: a synthetic purine antimetabolite with significant activity against lymphoid malignancies. J Clin Oncol 9: 175-188, 1991.

5. Ross SR, McTavish D and Faulds D: Fludarabine. A review of its pharmacological properties and therapeutic potential in malignancy. Drugs 45: 737-759, 1993.

6. Rodriguez G: Fludarabine phosphate. A new anticancer drug with significant activity in patients with chronic lymphocytic leukemia and in patients with lymphoma. Invest New Drugs 12: 75-92, 1994.

7. Keating MJ, McLaughlin P, Plunkett W, Robertson LE, O'Brien S, Gandhi V, Gregoire V, Yang L and Cabanillas F: Fludarabinepresent status and future developments in chronic lymphocytic leukemia and lymphoma. Ann Oncol 5 (Suppl. 2): 79-83, 1994.

8. Malspeis L, Grever MR, Staubus AE and Young D: Pharmacokinetics of 2-F-ara-A (9-beta-D-arabinofuranosyl-2-fluoroadenine) in cancer patients during the phase I clinical investigation of fludarabine phosphate. Semin Oncol 17: 18-32, 1990.

9. Danhauser L, Plunkett W, Keating $M$ and Cabanillas F: 9-betaD-arabinofuranosyl-2-fluoroadenine 5'-monophosphate pharmacokinetics in plasma and tumor cells of patients with relapsed leukemia and lymphoma. Cancer Chemother Pharmacol 18: 145-152, 1986.

10. Brachwitz H, Bergmann J, Thomas Y, Wollny T and Langen P: Synthesis and antiproliferative potency of 9-beta-D-arabinofuranosyl-2-fluoroadenine phospholipid adducts. Bioorg Med Chem 7: 1195-1200, 1999.

11. Barrueco JR, Jacobsen DM, Chang CH, Brockman RW and Sirotnak FM: Proposed mechanism of therapeutic selectivity for 9-beta-D-arabinofuranosyl-2-fluoroadenine against murine leukemia based upon lower capacities for transport and phosphorylation in proliferative intestinal epithelium compared to tumor cells. Cancer Res 47: 700-706, 1987.

12. Gandhi V and Plunkett W: Cellular and clinical pharmacology of fludarabine. Clin Pharmacokinet 41: 93-103, 2002.

13. Montillo M, Ricci F and Tedeschi A: Role of fludarabine in hematological malignancies. Expert Rev Anticancer Ther 6: 1141-1161, 2006.

14. Huang $P$, Chubb $S$ and Plunkett $W$ : Termination of DNA synthesis by 9-beta-D-arabinofuranosyl-2-fluoroadenine. A mechanism for cytotoxicity. J Biol Chem 265: 16617-16625, 1990 . 
15. Huang P, Sandoval A, Van Den NE, Keating MJ and Plunkett W: Inhibition of RNA transcription: a biochemical mechanism of action against chronic lymphocytic leukemia cells by fludarabine. Leukemia 14: 1405-1413, 2000.

16. Krawczyk B, Rudnicka K and Fabianowska-Majewska K: The effects of nucleoside analogues on promoter methylation of selected tumor suppressor genes in MCF-7 and MDA-MB-231 breast cancer cell lines. Nucleosides Nucleotides Nucleic Acids 26: 1043-1046, 2007.

17. Van Den Neste E, Cardoen S, Offner F and Bontemps F: Old and new insights into the mechanisms of action of two nucleoside analogs active in lymphoid malignancies: fludarabine and cladribine (Review). Int J Oncol 27: 1113-1124, 2005.

18. May P and May E: Twenty years of p53 research: structural and functional aspects of the p53 protein. Oncogene 18: 7621-7636, 1999.

19. Thomas M, Finnegan CE, Rogers KM, Purcell JW, Trimble A, Johnston PG and Boland MP: STAT1: a modulator of chemotherapy-induced apoptosis. Cancer Res 64: 8357-8364, 2004.

20. Battle TE and Frank DA: The role of STATs in apoptosis. Curr Mol Med 2: 381-392, 2002

21. Widschwendter A, Tonko-Geymayer S, Welte T, Daxenbichler G, Marth C and Doppler W: Prognostic significance of signal transducer and activator of transcription 1 activation in breast cancer. Clin Cancer Res 8: 3065-3074, 2002.

22. Ding X, Herzlich AA, Bishop R, Tuo J and Chan CC: Ocular toxicity of fludarabine: a purine analog. Expert Rev Ophthalmol 3: 97-109, 2008

23. Kaplow R: Innovations in antineoplastic therapy. Nurs Clin North Am 40: 77-94, 2005.

24. Pierige F, Serafini S, Rossi L and Magnani M: Cell-based drug delivery. Adv Drug Deliv Rev 60: 286-295, 2008.

25. Fraternale A, Rossi L and Magnani M: Encapsulation, metabolism and release of 2-fluoro-ara-AMP from human erythrocytes. Biochim Biophys Acta 1291: 149-154, 1996.

26. Magnani M, Rossi L, Brandi G, Schiavano GF, Montroni M and Piedimonte G: Targeting antiretroviral nucleoside analogues in phosphorylated form to macrophages: in vitro and in vivo studies. Proc Natl Acad Sci USA 89: 6477-6481, 1992.

27. Lowry OH, Rosebrough NJ, Farr AL and Randall RJ: Protein measurement with the Folin phenol reagent. J Biol Chem 193 $265-275,1951$

28. Laemmli UK: Cleavage of structural proteins during the assembly of the head of bacteriophage T4. Nature 227: 680-685, 1970.

29. Towbin H, Staehelin T and Gordon J: Electrophoretic transfer of proteins from polyacrylamide gels to nitrocellulose sheets: procedure and some applications. Proc Natl Acad Sci USA 76: 4350-4354, 1979.

30. O'Connor PM, Jackman J, Bae I, Myers TG, Fan S, Mutoh M, Scudiero DA, Monks A, Sausville EA, Weinstein JN, Friend S, Fornace AJ Jr and Kohn KW: Characterization of the p53 tumor suppressor pathway in cell lines of the National Cancer Institute anticancer drug screen and correlations with the growth-inhibitory potency of 123 anticancer agents. Cancer Res 57: 4285-4300, 1997.

31 Youlyouz-Marfak I, Gachard N, Le CC, Najjar I, BaranMarszak F, Reminieras L, May E, Bornkamm GW, Fagard R and Feuillard J: Identification of a novel p53-dependent activation pathway of STAT1 by antitumour genotoxic agents. Cell Death Differ 15: 376-385, 2008.

32. Pellegrini $\mathrm{S}$ and Dusanter-Fourt I: The structure, regulation and function of the Janus kinases (JAKs) and the signal transducers and activators of transcription (STATs). Eur J Biochem 248: 615-633, 1997.
33. Ihle JN: STATs: signal transducers and activators of transcription. Cell 84: 331-334, 1996.

34. Ramana CV, Chatterjee-Kishore M, Nguyen H and Stark GR: Complex roles of Stat1 in regulating gene expression. Oncogene 19: 2619-2627, 2000

35. Lathan B, Diehl V, Clark GM and von Hoff DD: Cytotoxic activity of 9-beta-D-arabinofuranosyl-2-fluoroadenine 5-monophosphate (fludarabine, NSC 312887) in a human tumor cloning system. Eur J Cancer Clin Oncol 24: 1891-1895, 1988.

36. Mittelman A, Ashikari R, Ahmed T, Savona S, Arnold P and Arlin Z: Phase II trial of fludarabine phosphate (F-Ara-AMP) in patients with advanced breast cancer. Cancer Chemother Pharmacol 22: 63-64, 1988.

37. Magnani M, Rossi L, D'ascenzo M, Panzani I, Bigi L and Zanella A: Erythrocyte engineering for drug delivery and targeting. Biotechnol Appl Biochem 28: 1-6, 1998.

38. Rossi L, Castro M, D'Orio F, Damonte G, Serafini S, Bigi L, Panzani I, Novelli G, Dallapiccola B, Panunzi S, Di CP, Bella S and Magnani M: Low doses of dexamethasone constantly delivered by autologous erythrocytes slow the progression of lung disease in cystic fibrosis patients. Blood Cells Mol Dis 33: 57-63, 2004.

39. Castro M, Rossi L, Papadatou B, Bracci F, Knafelz D, Ambrosini MI, Calce A, Serafini S, Isacchi G, D'Orio F, Mambrini G and Magnani M: Long-term treatment with autologous red blood cells loaded with dexamethasone 21-phosphate in pediatric patients affected by steroid-dependent Crohn disease. J Pediatr Gastroenterol Nutr 44: 423-426, 2007.

40. Bossa F, Latiano A, Rossi L, Magnani M, Palmieri O, Dallapiccola B, Serafini S, Damonte G, De Santo E, Andriulli A and Annese V: Erythrocyte-mediated delivery of dexamethasone in patients with mild-to-moderate ulcerative colitis, refractory to mesalamine: a randomized, controlled study. Am J Gastroenterol 103: 2509-2516, 2008

41. Annese V, Latiano A, Rossi L, Lombardi G, Dallapiccola B, Serafini S, Damonte G, Andriulli A and Magnani M: Erythrocytes-mediated delivery of dexamethasone in steroid-dependent IBD patients-a pilot uncontrolled study. Am J Gastroenterol 100: 1370-1375, 2005.

42. Rossi L, Serafini S, Cenerini L, Picardi F, Bigi L, Panzani I and Magnani M: Erythrocyte-mediated delivery of dexamethasone in patients with chronic obstructive pulmonary disease. Biotechnol Appl Biochem 33: 85-89, 2001.

43. Janicke RU, Ng P, Sprengart ML and Porter AG: Caspase-3 is required for alpha-fodrin cleavage but dispensable for cleavage of other death substrates in apoptosis. J Biol Chem 273: 15540-15545, 1998.

44. Kurokawa H, Nishio K, Fukumoto H, Tomonari A, Suzuki T and Saijo N: Alteration of caspase-3 (CPP32/Yama/apopain) in wild-type MCF-7, breast cancer cells. Oncol Rep 6: 33-37, 1999.

45. Yang XH, Sladek TL, Liu X, Butler BR, Froelich CJ and Thor AD: Reconstitution of caspase 3 sensitizes MCF-7 breast cancer cells to doxorubicin- and etoposide-induced apoptosis. Cancer Res 61: 348-354, 2001.

46. Baran-Marszak F, Feuillard J, Najjar I, Le CC, Bechet JM, Dusanter-Fourt I, Bornkamm GW, Raphael M and Fagard R: Differential roles of STAT1alpha and STAT1beta in fludarabineinduced cell cycle arrest and apoptosis in human B cells. Blood 104: 2475-2483, 2004

47. Kim HS and Lee MS: STAT1 as a key modulator of cell death. Cell Signal 19: 454-465, 2007.

48. Gooch JL, Herrera RE and Yee D: The role of p21 in interferon gamma-mediated growth inhibition of human breast cancer cells. Cell Growth Differ 11: 335-342, 2000. 